\title{
Use of continuous wave Doppler ultrasound velocimetry to assess the severity of coarctation of the aorta by measurement of aortic flow velocities
}

\author{
R K H WYSE, P J ROBINSON, J E DEANFIELD, D S TUNSTALL PEDOE, * \\ F J MACARTNEY \\ From the Department of Paediatric Cardiology, Institute of Child Health, and the ${ }^{\star}$ Department of Cardiology, St \\ Bartholomew's Hospital, London
}

SUMMARY Peak ascending and descending aortic blood flow velocities were measured using continuous wave Doppler ultrasound velocimetry in 30 children with coarctation or recoarctation of the aorta and in 13 control subjects. The results were compared with the arm to leg systolic blood pressure difference. The peak flow velocities in the descending aorta were significantly higher in the patients than in the control subjects and there was a close correlation with the systolic blood pressure gradient. Since there was no overlap of flow velocities between the patients and the control subjects the Doppler technique enables coarctation confidently to be excluded as well as demonstrating its presence and severity. The method is simple, rapid, independent of the condition of the aortic valve, and is applicable to neonates in whom the diagnosis of coarctation may otherwise be difficult. In older children it is useful for detecting recoarctation and following its progress, particularly in patients in whom a reliable estimate of the systolic blood pressure gradient cannot be obtained.

Initial diagnosis and assessment of coarctation of the aorta is usually based on the quality of the femoral pulses and the blood pressure difference between the arm and the leg. Cardiac catheterisation and angiocardiography have been the traditional means of investigation in infants. Cross sectional echocardiography has enabled accurate non-invasive diagnosis in many congenital heart lesions, but in patients with coarctation it may be unable to determine the site of the lesion ${ }^{1}$ and thus cannot be used to estimate severity by assessing lumen diameter. Using the Bernoulli equation transcutaneous Doppler ultrasound velocimetry has been used successfully to estimate the fall in pressure across valvular lesions. ${ }^{23}$ In this study, we aimed to determine whether this type of Doppler approach might add clinically useful information for the non-invasive assessment of patients with coarctation of the aorta, a lesion which represents a form of obstruction rather different from the valvular stenoses. We have used the technique in

Requests for reprints to Dr R K H Wyse, Department of Paediatric Cardiology, Institute of Child Health, 30 Guilford Street, London WCIN 1EH.

Accepted for publication 5 April 1984 patients with coarctation over a wide age range including neonates and children both before and after surgery.

\section{Patients and methods}

Thirty patients with coarctation of the aorta were studied. The mean (SD) age of these patients was $7 \cdot 2$ $(0.8)$ years (range 8 days to 16.8 years). Thirteen were aged under 6 years, and three of these were less than 3 months old. Seven patients with coarctation were evaluated before surgery, and the remaining 24 studies (one neonate was studied before and after surgery) were carried out $5.4(0.8)$ years after repair (range 2 days to 13.3 years). In five of these, recoarctation was suspected clinically. Doppler and blood pressure studies were also performed in a control group of 13 children without coarctation (range 5 weeks to 13.8 years; mean $6.8(1.3)$ years).

The three patients under 3 months of age were all severely symptomatic and underwent coarctation repair within $\mathbf{4 8}$ hours of admission. In each case, cross sectional echocardiography showed normal preoperative left ventricular function and no associated 
intracardiac lesions apart from mild thickening of the aortic valve. All the other patients in the study were clinically well.

\section{BLOOD FLOW MEASUREMENTS}

The peak velocity of blood flow in the ascending and descending aorta was measured in children with coarctation or recoarctation of the aorta using a combined pulsed and continuous wave Doppler velocimeter (either an ALFRED system, Vingmed A/S Ltd, Norway; or in two patients a similar PEDOF system, Vingmed A/S Ltd, Norway, with peak velocity read from a dedicated online spectral display ${ }^{4}$ (Fig. 1)). The ALFRED system was equipped with a digital display maximum frequency estimator, which gives a value for peak blood flow velocity each cardiac cycle. The Doppler velocimeter was used in its continuous wave mode in these patients since the velocities obtained from the site of coarctation exceeded the resolution capabilities of the pulsed alternative. The emitting frequency was $2 \mathrm{MHz}$ which allowed the maximum resolvable velocity in the continuous wave mode to be $8.1 \mathrm{~m} / \mathrm{s}$. A spectral analyser (Angioscan, Unigon Industries Inc, Mt Vernon, NY, USA) was also used in six patients as an adjunct to evaluate the ALFRED continuous wave Doppler signals and compare the reproducibility of recorded blood flow velocity waveforms.

Studies were performed with the patient supine. The peak flow velocities in the ascending and descending limbs of the aorta were measured from the suparasternal notch using an angulated $\left(45^{\circ}\right)$ transducer. Using the audio output the continuous wave Doppler beam was directed towards the descending aorta and the transducer position adjusted until a reproducible clear maximum signal was heard. Using the maximum frequency estimator the values for maxi-
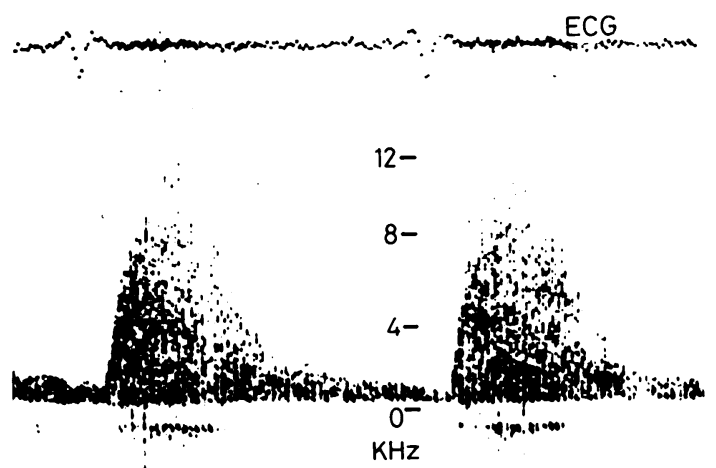

Fig. 1 Spectral display obtained by the continuous wave Doppler ultrasonic evaluation of blood flow in the descending aorta of a patient with recoarctation of the aorta. The Doppler shift in $\mathrm{kHz}$ is equivalent to a peak blood flow velocity of $3.5 \mathrm{~m} / \mathrm{s}$. mum flow velocity were obtained over many $(>50)$ cardiac cycles, and the range of these values was noted together with the overall peak velocity, the value of which was subsequently used to calculate the predicted pressure gradient (see later). This procedure was then repeated by directing the Doppler beam towards the ascending aorta to obtain values for the maximum blood flow velocity, noting the range as well as the overall fastest velocity recorded. The Doppler signal was not corrected for angle since this was small for both limbs of the aorta studied. In a few patients respiration caused the lungs periodically to obstruct the direct ultrasonic route between transducer and coarctation; this effect could often be eliminated if patients were asked to turn their head to the left.

\section{MEASUREMENT OF SYSTOLIC BLOOD PRESSURE GRADIENT}

After the maximum flow velocities had been determined, the right arm to leg blood pressure gradient was measured using appropriately sized cuffs and a continuous wave transcutaneous Doppler ultrasound peripheral blood velocimeter (BV 381, Sonicaid Ltd, Sussex, UK) with an emitting frequency of $7.5 \mathrm{MHz}$.

The maximum blood flow velocity measured in the descending aorta was used in this study to estimate the systolic blood pressure gradient because the peak blood flow jet velocity at a stenosis is known to be proportional to the pressure gradient driving it. ${ }^{5}$ This relation is described by a derivation of the Bernoulli equation which relates the fall in pressure to the difference between the squares of the upstream and jet velocities multiplied by a constant. Since blood flow proximal to a stenosis is usually much slower than at the jet, however, the equation conveniently reduces to the more simplified form used in this study: $\left(P_{1}-P_{2}\right)=4 V^{2}$ where $\left(P_{1}-P_{2}\right)$ represents the systolic pressure difference and $\mathrm{V}$ the maximum jet velocity.

\section{STATISTICAL ANALYSIS}

All statistical results were calculated on an Amdahl mainframe computer using a statistical package (SPSS version 7.0) and standard $t$ test and linear regression analysis. Results are given as means and standard errors of the mean (SEM).

\section{Results}

BLOOD PRESSURE FINDINGS

In the patients with unoperated coarctation the range of arm to leg systolic blood pressure gradients was $22-75 \mathrm{~mm} \mathrm{Hg}$. In postoperative patients this range was $4-50 \mathrm{~mm} \mathrm{Hg}$. In the control subjects the range was -10 to $+5 \mathrm{~mm} \mathrm{Hg}$. 
Of the 30 patients with coarctation, five had systolic pressures in the right arm that were $\geqslant 160 \mathrm{~mm} \mathrm{Hg}$. In a further eight, this pressure was between 140 and $160 \mathrm{~mm} \mathrm{Hg}$.

\section{BLOOD VELOCITY MEASUREMENTS}

Measurements of peak ascending and descending aortic blood flow velocities were successfully obtained in all 31 studies. In patients with coarctation the peak flow velocity in the descending aorta was significantly higher than in the control subjects $(\mathbf{p}<0.001)$ (Fig. 2 and Table). There was no overlap between the two groups.

The arm to leg systolic pressure gradient in patients with coarctation was plotted against peak descending aortic flow velocity in Fig. 3; linear regression gave a coefficient of correlation of $0.84(p<0.001)$. The arm to leg systolic pressure difference in these patients was also plotted against the pressure gradient predicted by the Doppler technique, which was calculated from the values of peak blood flow velocities in the decending aorta using the simplified Bernoulli equation. There was a significant correlation between the two $(r=0.85$; p $<0.001$ ) (Fig. 4).

In patients with coarctation the peak flow velocity in the ascending aorta was significantly higher than in the control subjects $(\mathbf{p}<0.001)$ (Fig. 2 and Table), and $83 \%$ of these values were above the range found in the control group. Two of the patients had both significant aortic stenosis and coarctation, whereas

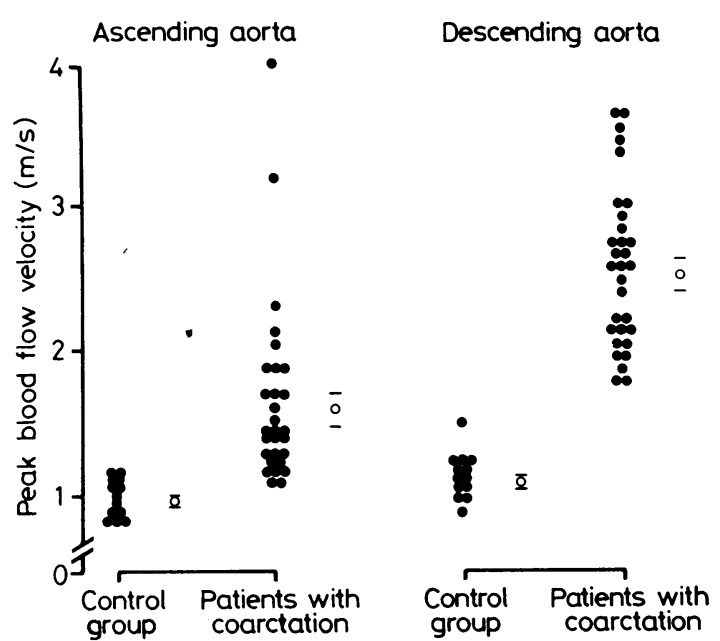

Fig. 2 Range of blood flow velocities in the ascending and descending limbs of the aorta in patients with coarctation $(n=31)$ compared with those in control subjects $(n=13)$. Two patients with coarctation also had significant aortic stenosis and this is reflected in the flow values for the ascending aorta. (O) denotes mean value; bars represent $S E M$.

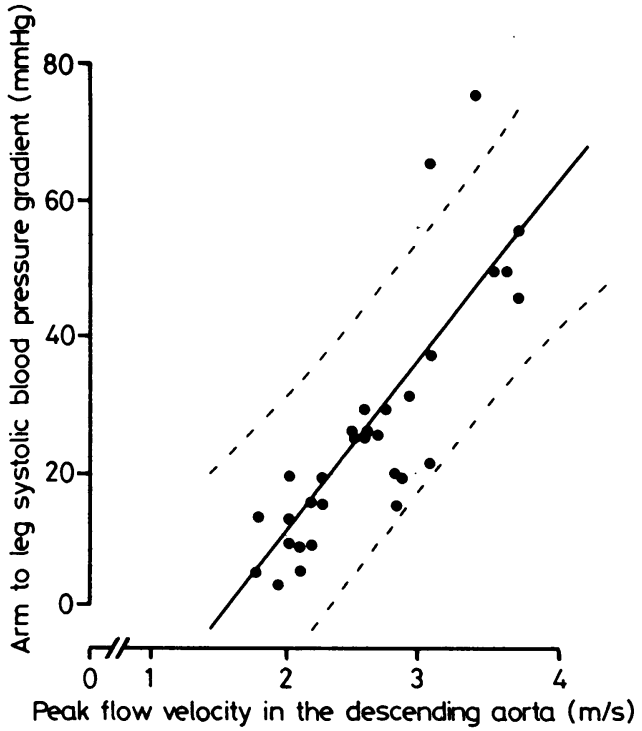

Fig. 3 Relation between the arm to leg systolic blood pressure gradient and the peak blood flow velocity in the descending aorta in patients with coarctation. The regression line $(r=0.84$; $p<0.001 ; n=31$ ) is shown with $95 \%$ confidence limits.

many others were known to have abnormalities of the aortic valve (such as bicuspid valve), which are commonly associated with coarctation.
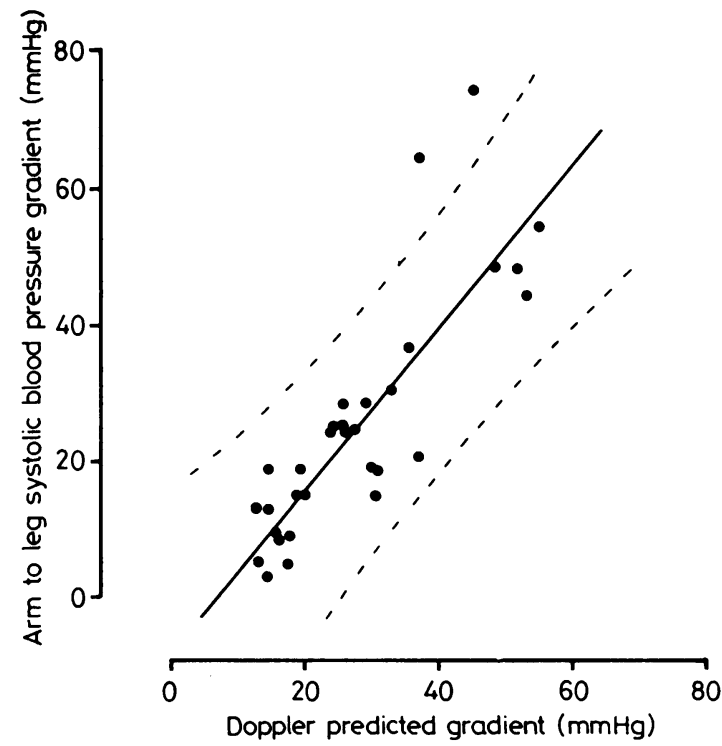

Fig. 4 Relation between the systolic blood pressure gradient and the gradient as predicted by using the simplified Bernoulli equation from Doppler ultrasound blood flow measurements in the descending aorta in patients with coarctation. The regression line $(r=0.85 ; p<0.001 ; n=31)$ is shown with $95 \%$ confidence limits. 
Table Systolic blood pressure gradients and aortic flow velocities in 30 patients with coarctation (one neonate was studied twice) and 13 control subjects

\begin{tabular}{|c|c|c|c|c|c|}
\hline \multicolumn{3}{|c|}{ Systolic blood pressure (mm $\mathrm{Hg})$} & \multicolumn{2}{|c|}{ Flow velocities $(\mathrm{m} / \mathrm{s})$} & \multirow{2}{*}{$\begin{array}{l}\text { Operative } \\
\text { status }\end{array}$} \\
\hline Arm & Leg & $\begin{array}{l}\text { Arm to leg } \\
\text { gradient }\end{array}$ & $\begin{array}{l}\text { Descending } \\
\text { aorta }\end{array}$ & $\begin{array}{l}\text { Ascending } \\
\text { aorta }\end{array}$ & \\
\hline $\begin{array}{l}125 \\
140 \\
105 \\
114 \\
122 \\
130 \\
170 \\
140 \\
115 \\
120 \\
175 \\
160 \\
145 \\
135 \\
92 \\
124 \\
124 \\
130 \\
144 \\
146 \\
115 \\
110 \\
145 \\
195 \\
120 \\
125 \\
140 \\
140 \\
130 \\
180 \\
120 \\
\text { Mean (SEM) }\end{array}$ & $\begin{array}{r}110 \\
130 \\
90 \\
108 \\
90 \\
101 \\
150 \\
65 \\
95 \\
105 \\
110 \\
140 \\
115 \\
110 \\
82 \\
120 \\
74 \\
108 \\
130 \\
132 \\
90 \\
85 \\
120 \\
140 \\
115 \\
80 \\
120 \\
115 \\
93 \\
130 \\
110\end{array}$ & $\begin{array}{r}15 \\
10 \\
15 \\
6 \\
32 \\
29 \\
20 \\
75 \\
20 \\
15 \\
65 \\
20 \\
30 \\
25 \\
10 \\
4 \\
50 \\
22 \\
14 \\
14 \\
25 \\
25 \\
25 \\
55 \\
5 \\
45 \\
20 \\
25 \\
37 \\
50 \\
10\end{array}$ & $\begin{array}{l}\text { coarctation } \\
2.23 \\
2.03 \\
2.20 \\
1.80 \\
2.92 \\
2.59 \\
2.25 \\
3.40 \\
2.80 \\
2.80 \\
3.08 \\
2.80 \\
2.70 \\
2.67 \\
2.18 \\
1.90 \\
3.58 \\
3.05 \\
1.98 \\
1.79 \\
2.59 \\
2.49 \\
2.45 \\
3.72 \\
2.12 \\
3.67 \\
1.98 \\
2.59 \\
3.00 \\
3.50 \\
2.09 \\
2.61(0.1)\end{array}$ & $\begin{array}{l}1.40 \\
1.43 \\
1.30 \\
1.70 \\
1.30 \\
1.10 \\
1.85 \\
1.40 \\
1.70 \\
1.48 \\
1.50 \\
1.20 \\
2.30 \\
1.20 \\
1.28 \\
1.59 \\
1.20 \\
2.10 \\
2.20 \\
3.23 \\
1.05 \\
1.30 \\
1.92 \\
1.28 \\
1.48 \\
1.68 \\
1.90 \\
4.04 \\
\frac{-}{1} \\
1.48 \\
1.68(0.12)\end{array}$ & $\begin{array}{l}P \\
P \\
P P \\
P \\
P R \\
P \\
P \\
U \\
P \\
P \\
U \\
P P \\
P P \\
P \\
P \\
P \\
U \\
U \\
P \\
P R \\
P \\
P \\
U \\
U \\
P \\
P R \\
P \\
U \\
P R \\
P R \\
P\end{array}$ \\
\hline $\begin{array}{l}120 \\
130 \\
135 \\
95 \\
100 \\
135 \\
125 \\
140 \\
170 \\
134 \\
130 \\
108 \\
108 \\
\text { Mean (SEM) }\end{array}$ & $\begin{array}{l}120 \\
130 \\
135 \\
105 \\
105 \\
130 \\
120 \\
135 \\
170 \\
133 \\
130 \\
110 \\
110\end{array}$ & $\begin{array}{r}0 \\
0 \\
0 \\
-10 \\
-5 \\
5 \\
5 \\
5 \\
0 \\
1 \\
0 \\
-2 \\
-2\end{array}$ & $\begin{array}{l}\text { group } \\
1.16 \\
1.12 \\
1.25 \\
1.15 \\
1.15 \\
1.09 \\
0.93 \\
1.26 \\
1.20 \\
1.24 \\
0.95 \\
0.95 \\
1.55 \\
1.15(0.05)\end{array}$ & $\begin{array}{l}1.02 \\
0.80 \\
1.20 \\
1.00 \\
0.85 \\
1.17 \\
0.87 \\
1.18 \\
1.10 \\
1.10 \\
0.85 \\
0.92 \\
1.21 \\
1.02(0.04)\end{array}$ & \\
\hline
\end{tabular}

P, postoperative; PR, postoperative but recoarctation has developed; U, unoperated; PP, post-coarctation and recoarctation repairs.

\section{Discussion}

Primary clinical diagnosis and subsequent assessment of the severity of coarctation and recoarctation of the aorta has traditionally been based on the judgment of the character of the femoral pulse. Nevertheless, absent, weakened, or delayed femoral pulses occurring in coarctation are a secondary event, which is manifested as a result of the obstruction. We report a simple, rapid, non-invasive method for detecting coarctation and recoarctation based on a direct ultrasonic evaluation of blood flow at the obstructive site.

We found this Doppler approach to be useful in several ways. It can establish rapidly the presence or absence of coarctation. It is simple, quick, and suitable both for neonates and children and will detect coarctation and recoarctation equally well. Furthermore, a measure of the severity of the lesion may be derived from the peak blood flow velocity in the descending aorta, from which the systolic pressure gradient may also be reliably estimated. Furthermore, 
as we found no overlap of range between the flow velocities in the descending aorta of patients compared with those of the control group, finding a normal peak flow velocity in a child will, therefore, positively exclude the presence of coarctation. The range of blood flow velocities in the descending aorta in our control group was similar to values obtained in a large published series of children," and the flow velocity appears to be independent of age.

Although an accurate assessment of the fall in pressure from an estimation of the jet velocity has been claimed in two patients, ${ }^{7}$ no systemic study of a sufficiently large series is available to validate the technique in coarctation. We found in the present study that when the Doppler technique is used to assess children with coarctation the Bernoulli equation may be used confidently to estimate the pressure gradient. Moreover, even more simply, without using the Bernoulli relation, just measuring the value of the peaiz blood flow velocity in the descending aorta is indeed all that is required to establish whether significant obstruction is present or not and to assess its severity (Fig. 3).

We have shown that coarctation can be detected by the continuous wave Doppler technique in the presence of even severe aortic stenosis. Many of our other patients were previously known also to have minor abnormalities of the aortic valve, which are commonly associated with coarctation. These abnormalities are likely to be the explanation for the modest increases in peak ascending aortic blood flow velocities. Using the Doppler technique, however, we were able to distinguish the lesions separately from the peak blood flow jet velocities in the two sites studied. It was apparent from some of our other studies that in patients with severe aortic stenosis and no coarctation the flow velocity in the descending aorta was quite normal. ${ }^{8}$ The high velocity jet associated with aortic stenosis is dissipated by the time the blood reaches the descending aorta, and our findings with the Doppler velocimeter confirm earlier systematic studies using thin film anemometers, either catheter mounted or (during surgery) needle mounted. These have shown that the jet of aortic stenosis persists for only a few centimetres above the valve and that the turbulence persists only in the form of low velocity eddies beyond the aortic arch. ${ }^{y}$ It was deduced from these observations that ascending aortic peak blood flow velocity, when measured by the continuous wave Doppler technique, could not be used in the unsimplified Bernoulli equation as a value for blood flow proximal to the jet. If measurement of velocity upstream to the coarctation were required a pulsed Doppler system (sampling beyond the jet of aortic stenosis but before the coarctation) would be necessary. In practice, however, the simplified Bernoulli equation omitting proximal flow was found in this study to predict the coarctation systolic pressure gradient extremely well.

In postoperative patients, by quantifying flow velocities, longitudinal assessment is facilitated making it easier to detect recoarctation and follow its progress. This is particularly true in patients who have had arterial catheterisation from the right arm and subclavan flap repairs on the left, for in such patients it may be impossible to obtain reliable non-invasive measures of blood pressure proximal to the coarctation. Furthermore, Doppler velocimetry might well prove extremely useful in interpreting the recent finding that $69 \%$ of patients immediately after coarctation repair have an arm to leg pressure difference that subsequently resolves, whereas only $13 \%$ have persistent gradients and $13 \%$ progressive gradients. ${ }^{10} \mathrm{We}$ do not know whether these pressure differences represent obstruction to flow or whether they are simply the result of alterations in the elasticity of the aortic wall.

Even in patients with what we would consider as extremely good coarctation repairs (that is, with gradients $<10 \mathrm{~mm} \mathrm{Hg}$ ) the range of jet velocities at the coarctation site was increased. Since these velocities are twice the normal values it is possible that these patients have a reduction in lumen diameter at the site of coarctation but that it is not severe enough to create a significant gradient.

We were concerned that when the operator used the audio output without spectral analysis the peak frequency estimator in the ALFRED might overestimate the flow velocities. Nevertheless, the ear is extremely sensitive in detecting artefactual flow velocity waveforms and in allowing the transducer beam to settle on the fastest part of any jet. We were therefore able to obtain consistent results over many cardiac cycles. When a spectral analyser was used in some patients there was always consistency between the spectral output and the peak velocity estimates. Thus we concluded that the continuous wave Doppler technique can be used confidently for the accurate reliable evaluation of flow velocities in the aorta and may be used confidently without a spectral analyser by listening to the audio output alone. A dedicated continuous wave Doppler system is not only quick and simple but has other advantages over a pulsed system with imaging capability. Pulsed systems generally are unable to resolve the high velocities associated with stenotic lesions, and those that are designed to do so (multiple sample volume devices) are, in our experience, inappropriate for use in neonates because the ultrasound transit time is too short. Furthermore, in neonates the small size of the angulated transducer head in the continuous wave system makes suprasternal Doppler studies much easier than with a bulkier imaging transducer.

We have found in two neonates that the continuous 
wave Doppler technique considerably underestimated the large pressure gradient at the coarctation site. This was probably due to the encroachment of the lungs, which prevented the ultrasound beam from insonating the fastest part of the jet. In both these neonates, however, the measured flow velocities were still in excess of $3.0 \mathrm{~m} / \mathrm{s}$ and thus were still unmistakably diagnostic of coarctation.

In summary, continuous wave Doppler ultrasound velocimetry has proved to be rapid, reproducible, and accurate in recognising the presence or absence of coarctation or recoarctation of the aorta. It has also been helpful in evaluating the severity of this lesion. We consider that it is of value both in a ward receiving emergency admissions of neonates with congenital heart disease and at follow up, when it permits the severity of obstruction to be quantified directly.

RKHW and FJM are supported by the Vandervell and British Heart Foundations and PJR by the Wellcome Foundation.

\section{References}

1 Smallhorn JF, Huhta JC, Adams PA, Anderson RH, Wilkinson JL, Macartney FJ. Cross-sectional echocar- diographic assessment of coarctation in the sick neonate and infant. Br Heart $\mathcal{F}$ 1983; 50: 349-61.

2 Hatle L, Angelsen BA, Tromsdal A. Non-invasive assessment of aortic stenosis by Doppler ultrasound. $\mathrm{Br}$ Heart f 1980; 43: 284-92.

3 Hatle L. Noninvasive assessment and differentiation of left ventricular outflow obstruction with Doppler ultrasound. Circulation 1981; 64: 381-7.

4 Macpherson P, Meldrum SJ, Tunstall Pedoe DS. A real time spectrum analyser for ultrasonic Doppler signals using a Chirp-Z-transform technique. $\mathcal{F}$ Med Eng Technol $1980 ; 4: 24-6$.

5 Hatle L, Angelsen BA. Doppler ultrasound in cardiology. Philadelphia: Lea and Febiger, 1982.

6 Light LH. Implications of aortic blood velocity measurements in children. $\mathcal{F}$ Physiol (Lond) 1978; 285: 17-8P.

7 Tunstall Pedoe DS, Macpherson P. Cardiac diagnosis using continuous wave Doppler and a true spectral display. In: Spencer MP, ed. Cardiac Doppler diagnosis. Boston: Martinus NJ, Hoff. 1983: 143-52.

8 Robinson PJ, Wyse RKH, Deanfield JE, Macartney FJ. Continuous wave Doppler ultrasound as an adjunct to cross sectional echocardiography in the diagnosis of critical left heart obstruction in neonates [Abstract]. $\mathrm{Br}$ Heart f 1984; 51: 684.

9 Tunstall Pedoe DS. Velocity distribution of blood flow in major arteries of animals and man. Oxford University, 1970. D Phil Thesis.

10 Waldman JD, Lamberti JJ, Goodman AH, et al . Coarctation in the first year of life. Patterns of postoperative effect. $\mathcal{F}$ Thorac Cardiovasc Surg 1983; 86: 9-17. 